\title{
KÃNS KÃNS KARÃ : O CANTO DO PICA-PAU
}

Rafael Castro de Souza*

RESUMO: Neste ensaio, tratamos de um pequeno trecho da narrativa "Fumaça do tabaco", mito do povo Huni Kuĩ presente no livro Shenipabu Miyui. Em um determinado momento dessa história, faz-se referência a um pica-pau cujo canto seria capaz de levar à morte aquele que o escuta. Propomos uma breve discussão sobre a (im)possibilidade de existência de um tal pássaro fora do âmbito literário, a partir de um excerto das Mitológicas de Lévi-Strauss. Apresentamos, em seguida, um aspecto do pensamento do filósofo Emanuele Coccia numa tentativa de equalizacáo entre o canto dos pássaros e a música humana, par perspectivismc perspectivismo ameerindio de Eduardo Viveiros de Castro. Nosso intuito e demonstrar que, mais do que um pássaro literário, o p ca-pau deste texto indigena e um ser existente real, que embor soe fantástico ao ouvido moderno, é perfeitamente concebível para o pensamento mítico do povo Huni Kuĩ.

PALAVRAS-CHAVE: Literatura Huni Kuĩ; Shenipabu Miyui; Mitológicas; Sensível.
* rafaelchinaski@gmail.com

Mestrando no Programa de Pós-Graduação em Estudos Literários da Faculdade de Letras da UFMG com o trabalho intitulado $A$ vida literatura Huni Kuĩ.

RESUMEN: En este ensayo, tratamos de una pequeña parte de la historia "Humo de Tabaco "mito del pueblo Huni Kuĩ presente en el libro Shenipabu Miyui. En un momento determinado de la historia, se hace referencia a un pájaro carpintero cuyo canto podría conducir a muerte a la persona que lo escucha. Proponemos una breve discusión sobre la (im)posibilidad de existencia de esta ave fuera del ámbito literario, a partir de un extracto de las Mythologiques de Leví-Strauss. Presentamos aquí, pues, una faceta del pensamiento del filósofo Emanuele Coccia, en un intento de igual el canto de los pajaros $y$ la música humana. Por fin reanudamos el discurso del antropólogo francés a la luz del perspectivismo amerindio de Eduardo Viveiros de Castro. Nuestro objeto es mostrar que, más que un pájaro literario, el pájaro carpintero en este texto indigena es un ser real existente, que aunque suene fantástico para el oído moderno, es perfectamente concebible para el pensamiento mítico del pueblo Huni Kuĩ.

PALABRAS-CLAVE: Literatura Huni Kuĩ; Shenipabu Miyui; Mythologiques; Sensible. 
1. Hãtxa Kuĩ, ou língua verdadeira, é a língua do povo Huni Kuĩ.

2. História dos antigos.

3. O trabalho de revisão final, que implica a tomada de decisão sobre grafias, pontuação e segmentação de palavras, foi coordenado por Joaquim Mana Kaxinawá, professor Huni Kuĩ e doutor em Linguística pela Universidade de Brasília com a tese Uma gramática da língua Hãtxa Kuĩ.
[...] até que o pensamento, guiado inconscientemente por detalhesinfimos, consiga abraçar o contorno do mito.

Lévi-Strauss

Os Huni Kuĩ, "gente verdadeira”, são um povo da floresta que habita a Amazônia Ocidental desde o sudeste peruano até o Brasil, no estado do Acre. Sua língua, o Hãtxa Kuĩ ${ }^{1}$, pertence à família linguística Pano. Desde há pelo menos duas décadas, os Huni Kuĩ tem publicado diversos livros, em língua portuguesa e na língua materna, como forma de fortalecimento de sua identidade étnica e de suas tradições $\mathrm{e}$ principalmente, como ferramenta da educação escolar e do estabelecimento da língua escrita. Um desses livros, que pode ser considerado um marco da literatura huni kuĩ, é chamado Shenipabu Miyui². Originalmente publicado pela Comissão Pró-Índio do Acre (CPI/AC) em 1995, o livro foi reeditado pela Editora UFMG em 2000, quando de sua adoção no vestibular. Shenipabu Miyui contém doze mitos huni kuĩ, em Hãtxa Kuĩ e em português, coletados pelos professores bilín gues junto aos mestres da tradição. Além de seu inegável valor literário, Shenipabu Miyui foi também uma importante experiência no processo, ainda em curso, de consolidação do Hãtxa Kuĩ escrito. ${ }^{3}$

Em Shenipabu Miyui há uma narrativa chamada "Fumaça do tabaco" - "Kuĩ Dume Teneni" - que, em sua versão em português, começa assim:
Tekã Kuru, um jovem como nós, fez um rapé de tabaco muito forte, o mais forte que tinha. Então, ele tomou o rapé. Pegou o canudo de taboca, botou o tabaco na mão e aspirou. Ficou bêbado e passou um ano na rede, ali deitado. Por isso que hoje em dia o tabaco é forte. Passou um ano curtindo. ${ }^{4}$

Um mitólogo que, pela primeira vez, pousasse os olhos sobre esse parágrafo sentiria-se, certamente, tentado a classificar o mito que o constitui como de caráter etiológico dedicado a explicar a razão para o fato de o tabaco ser forte nos dias de hoje. Esse mesmo mitólogo, ao continuar sua leitura, provavelmente se espantaria ao descobrir que, na verdade, esse início da narrativa é o único momento em que é feita menção ao tabaco no mito, a despeito do título a ele atribuído e de sua aparente vocação etiológica. Se tão pouco dessa história dos antigos é voltado para a explicação de algo extra-textual, essa não deve ser a função principal desse pequenho trecho. Com efeito, de um ponto de vista literário, esse episódio inicial de "Fumaça do tabaco" serve outra função mais importante no mito: é ele o fato motivador - se quisermos, uma etiologia intra-textual - dos acontecimentos que serão contados, a saber, a história de Tekã Kuru.

Em resumo, o mito nos conta: durante o período em que Tekã Kuru esteve bêbado em sua rede, sua esposa começou a namorar com um outro homem. Ao acordar de sua embriaguez que durou um ano, Tekã Kuru seguiu a esposa até o
4. KAXINAWA. Shenipabu Miyui, p. 41. 
5. KAXINAWÁ. Shenipabu Miyui, p. 42.

6. O contexto dessa nota é a discussão empreendida pelo antropólogo para justificar sua escolha pelas formas musicais como principal elemento estruturador das Mitológicas, assunto do qual tratamos em nossa introdução. roçado, local onde ela se encontrava com o amante, e matou ambos. Tomando uma prima como sua nova esposa, o jovem fugiu e iniciou uma série de viagens às diferentes aldeias onde viviam suas irmãs. Essas viagens resultaram em uma sucessão de combates heroicamente vencidos por Tekã Kuru, causando a morte de um homem encantado, de uma onça, de um gavião real, de um pica-pau, de um bicho que comia gente, de um macaco, de um bicho encantado de dois braços, do cunhado que comia fígado e de uma de suas irmãs. A história se encerra, então, com a morte do próprio Tekã Kuru.

Um pequeno detalhe desse mito, aparentemente irrelevante para o desenvolvimento da narrativa, chamou nossa atenção. Trata-se de uma advertência feita por uma das irmãs de Tekã Kuru no momento em que ele decide seguir viagem rumo a uma aldeia onde vive outra irmã. Ela diz: “Não, não vá, não! Lá no meio do caminho tem um pica-pau que, quando começa a cantar, ninguém consegue sobreviver ao seu canto." ${ }^{5}$ Essa fala despertou nossa curiosidade pois, até então, não sabíamos sequer que pica-pau cantava. Involuntariamente, essa descoberta nos remeteu a um trecho das Mitológicas, em que Lévi-Strauss discorre brevemente sobre o canto dos pássaros em uma nota de rodapé que está presente na abertura de $\mathrm{O}$ cru e o cozido. ${ }^{6}$

Embora os ornitólogos e os peritos em acústica concordem em reconhecer às emissões vocais dos pássaros o caráter de sons musicais, a hipótese, gratuita e inverificável, de uma relação genética entre o gorjeio e a música nem merece ser discutida. O homem não é o único produtor de sons musicais, ele compartilha esse privilégio com os pássaros, mas essa constatação não afeta a nossa tese, já que, à diferença da cor, que é um modo da matéria, a tonalidade musical - tanto entre os pássaros quanto entre os homens - é um modo da sociedade. O pretenso "canto" dos pássaros situa-se no limiar da linguagem; serve à expressão e à comunicação. Os sons musicais continuam, portanto, do lado da cultura. É a linha de demarcação entre a natureza e a cultura que já não segue tão exatamente quanto se acreditou no passado o traçado de nenhuma das linhas que servem para distinguir a humanidade da animalidade. ${ }^{7}$

Antes da leitura de "Fumaça do tabaco", essa nota de rodapé das Mitológicas já nos provocava um certo incômodo. Agora, retomando-a após o contato com a história de Tekã Kuru, o incômodo é ainda maior. Se antes ela soava a nossos ouvidos como um curioso arroubo antropocêntrico - uma vez que Lévi-Strauss rejeita veementemente qualquer "relação genética" entre o canto dos pássaros e a música humana agora ela parece negar a própria possibilidade de existência do pica-pau que nos é apresentado no mito. De acordo com o excerto acima, o que fazem os pássaros não é, em absoluto, um canto, e sim emissões vocais situadas no campo da linguagem, destinadas à comunicação e à expressão, que se
7. LÉVI-STRAUSS. O cru e o cozido p. 38-39. 
diferenciam da música humana e cuja relação com essa última seria uma questão que não mereceria sequer ser discutida. A existência de um pássaro que canta (produz música, não apenas sons musicais) é, pois, inconcebível para Lévi-Strauss. Que dizer então de um pássaro que, ao cantar, é capaz ainda de matar aquele que o escuta? Esse pica-pau, portanto, não pode exisitr.

O pensamento de Emanuele Coccia nos parece, à primeira vista, mais interessante para se pensar o canto dos pássaros. Para o filósofo, "nenhum dos traços que caracterizam a vida humana está ausente na vida sensível dos outros animais a distância é sempre e tão somente relativa ao grau e não à natureza"8. E

aquilo que caracteriza o vivente humano - e todos os animais, mesmo que de maneira diferente - é, então, a capacidade de produzir imagens de coisas: não uma praxis nem uma poiesis, senão uma esfera intermediária de relação e produção de sensível. Não se trata da faculdade de encarnar as formas em objetos, mas sim daquela de fazê-las viver momentaneamente fora das coisas e fora dos sujeitos. Os projetos, os desenhos, a música: grande parte das atividades espirituais humanas vivem, acima de tudo, dessa capacidade de fazer estacionar as formas nos meios antes que elas entrem novamente no mundo das coisas. ${ }^{9}$
O que Coccia nos permite entrever aqui é que a música pode existir também na vida animal, uma vez que se trata de uma produção de sensível - a que nós homens denominamos arte - tomada frequentemente como traço caracterizador da vida humana e "nenhum dos traços que caracterizam a vida humana está ausente na vida sensível dos outros animais". Se há diferenças entre a música humana e, por exemplo, o canto dos pássaros, essa diferença não é genética - como quis Lévi-Strauss - ou de natureza - termo usado por Coccia mas sim de grau. Essa diferença de grau significa a maior ou menor capacidade que os seres vivos possuem de produzir imagens e de se relacionar com elas. Assim, podemos supor que os pássaros apresentam uma capacidade idêntica a dos humanos de produzir música (um tipo de imagem, fenômeno sensível). A diferença entre esses animais e os homens, se quiséssemos instituir a todo custo uma diferença, residiria apenas no grau com que eles conseguem se relacionar com essas imagens. No limite, isso quer dizer que a elevação da música humana de simples matéria sonora ao estatuto de arte só é possível graças à nossa capacidade de nos relacionarmos em alto grau com as imagens que produzimos, uma espécie de vocação para a metalinguagem. Não nos esqueçamos que isso deflagra o outro lado da moeda: nossa incapacidade de nos relacionarmos com as imagens do outro, no caso, o outro (aparentemente) não-humano. Por isso Lévi-Strauss não vê música no canto dos pássaros. Ele parece 
10. Benedito Nunes, em seu artigo $O$ animal e o primitivo: os Outros de nossa cultura, nos lembra que para Descartes, o animal seria um corpo sem alma, "simples mecanismo" que se diferencia do homem principalmente pela ausência de consciência e pensamento. estar, como estamos quase todos, apegado demais - ainda que inconscientemente - a uma noção de animal por demais cartesiana $^{10}$, que furta da animalidade a capacidade inata a todos seres viventes de produzir e se nutrir do sensível.

Embora essa leitura do pensamento de Emanuele Coccia sirva para, de algum modo, equalizar a vida humana à vida animal e, dando um passo mais largo que o de Lévi-Strauss, possibilitar que ouçamos música no gorjeio de um pássaro, é importante que não nos apeguemos tanto assim a ela, tomando-a como definitiva e dando o assunto por encerrado, acreditando ter corrigido um suposto descuido do antropólogo francês. Afinal, Coccia não está preocupado em momento algum de sua obra com o canto dos pássaros e, embora ele equipare as instâncias animal e humana no nível da natureza, a balança volta a pesar em favor do humano quando o filósofo coloca em jogo o fator grau, instituindo, novamente, uma desigualdade em privilégio do homem. Uma quase equiparação entre o canto dos pássaros e a música, embora seja possível a partir do que propôs Coccia, não é suficiente para abarcar toda a complexidade do que nos foi apresentado naquele pequeno detalhe do mito huni kuĩ. Não importa o quanto nós torcermos (ou distorcermos) suas ideias, nunca conseguiremos caminhar para além dessa frágil equivalência. E é preciso ir além. Lembremo-nos que o canto do pica-pau da narrativa de Tekã Kuru é capaz de matar quem o escuta, potência essa que suplanta as próprias potencialidades da música. Falta em nossa equação, suspeitamos, algum elemento para além da música. A conta, portanto, no que diz respeito ao pica-pau do mito, está longe de fechar.

É possível que nesse momento passe pela cabeça daqueles que ora leem essas linhas um argumento bastante simples e supostamente capaz de invalidar toda a pertinência de nossa investigação: Lévi-Strauss falava certamente de pássaros "reais", enquanto o pica-pau a que fazemos referência é um pássaro literário, ficcional, mítico. ${ }^{11}$ De fato, estamos lidando aqui com uma narrativa denominada "Fumaça do tabaco", presente em um livro chamado "História dos antigos", que é de certo uma peça literária. Ela é, também e no entanto, assim como o todo livro que a contém, parte de um conjunto de obras que circulam por territórios não exclusivamente circunscritos pela literatura, visto tratar-se, em última análise, de textualidades - que, aliás, nem sempre são expressas sob a forma da língua escrita sobre as páginas de um livro - que deflagram mundos de visão de um povo, para falar com Eduardo Viveiros de Castro ${ }^{12}$, repletos de potenciais antropológicos, etnográficos, filosóficos e políticos, para dizer os mais evidentes. O que se conta nos mitos do povo Huni Kuĩ são histórias encaradas por eles próprios como fatos que ocorreram em algum momento da história anterior ao contato com os brancos. A própria língua hãtxa kuĩ
11. Todas essas, qualidades geralmente apresentadas como antônimos das palavras "real" ou "verdadeiro".

12. Em entrevista ao jornal $O$ Globo sobre seu livro (Metafísicas
canibais), Eduardo Viveiros canibais), Eduardo Viveiros chamei de 'multinaturalismo' ou de 'perspectivismo

multinaturalista' para as metáísicas indígens, supõe a indiscociabilidade radical, ou pressuposicão recíproca, ou 'mundo' e 'visão'. Não existem 'visões de mundo' (muitas visões 'visoes de mundo' (muitas visooes de um só mundo), mas mundos de visa, multiplicidanpostos es próprios, onde cado eles próprios, onde cada ser, visão no mundo do mu é visano no." Disponíve mundo - é mundo. Disponivel em: <http:// oglobo.globo.com/cultura/ castro-que-se-ve-no-brasil-hojecastro-que-se-ve-no-brasil-hoje-
uma-ofensiva-feroz-contra-osindios-17261624> 
possui um sufixo temporal exclusivo para referir-se a esse tempo antigo, o sufixo pauni, que marca um tempo muito distante, usado para falar de algo que não foi presenciado po aquele que diz mas foi transmitido a ele através das histórias contadas pelos velhos sábios. Assim, esse pica-pau da narrativa de Tekã Kuru é, para esse povo da floresta, não só um pássaro literário, mas um ser vivente. Por que razão deveríamos nós brancos encará-lo de maneira diferente, destituí-lo de qualquer autonomia ontológica e incorrer assim em um etnocentrismo maldoso e, no limite, fascista? Pensando dessa maneira, é difícil crer que Lévi-Strauss, talvez o mais importante nome da antropologia no âmbito da análise mítica, tenha cometido esse erro tão grosseiro justamente ao tratar dos mitos de centenas de povos ameríndios. Por isso, tornemos a ler a nota de rodapé em busca de uma chave de leitura qualquer que faça amenizar tal incômoda desconfiança.

Lévi-Strauss situa, em sua nota, a música humana e o gor jeio dos pássaros ambos no âmbito da cultura, posicionando esse último no limiar da linguagem. Ao mesmo tempo, ele rejeita qualquer relação genética entre os dois fenômenos. Por relação genética é possível compreendemos, com o aporte de Emanuele Coccia, uma relação de natureza, visto ser a natureza nada mais do que "a força que torna possível o nascimento das coisas". ${ }^{13}$ Nesse sentido, o que diz LéviStrauss é que há, nesse caso, uma só cultura para duas naturezas distintas. O antropólogo reforça sua tese ao afirmar que os traços distintivos entre natureza e cultura não são, como se acreditava no passado, os mesmos traços que distinguem a humanidade da animalidade. ${ }^{14}$ Quais traços seriam esses, não nos é revelado. Se ele ainda insiste nessa distinção, ele pelo menos admite que ela não pode mais ser pautada pelos mesmos parâmetros de distinção do binômio natureza e cultura, o que certamente vai de encontro ao pensamento de Emanuele Coccia do qual lançamos mão anteriormente. Esse pequeno movimento de Lévi-Strauss no sentido de enxergar múltiplas naturezas e apenas uma única cultura, ainda que tenha sido expresso timidamente em uma mera nota de rodapé, parece-nos de grande valia e talvez uma espécie de pilar conceitual sobre o qual desenvolveu-se uma teoria hoje bastante em voga no campo da antropologia, a saber o multinaturalismo, uma inversão conceitual do multiculturalismo ocidental. Enquanto nós, ocidentados - tomando emprestado o termo lacaniano - tendemos a acreditar na existência de uma natureza única habitada por uma pluralidade de culturas, para o pensamento ameríndio, ocorreria o contrário. A cultura é aquilo que é compartilhado por todos os seres existentes e a natureza é múltipla, encarnada nas diferentes formas - palavra essa, aliás, cara a Emanuele Coccia por ser um quase-sinônimo de imagem - que enxergamos ao olhar para o outro. O multinaturalismo é a mais importante implicação teórica do pespectivismo ameríndio, conceito cunhado pelos antropólogos Eduardo Viveiros de Castro e
14. Obviamente, Lévi-Strauss faz referência aqui à crença que perdurou durante muitos séculos nas ciências humanas de que a cultura a pedra-de-toque da separação entre o homem e os outros animais. Ou seja, enquanto toda vida animal pura e simplesmente natureza, o homem seria o único ser capaz de produzir (ou de avançar em direção à) cultura. 
Tânia Stolze Lima que vem ganhando cada vez mais espaço no campo dos estudos literários.

O breve discurso de Lévi-Strauss sobre o canto dos pássaros ganha então uma outra e mais interessante dimensão, chegando até mesmo a parecer, em certa medida, uma antecipação do que se entende hoje por multinaturalismo. Propomo-nos, então, a pensar o pica-pau huni kuĩ a partir da chave de leitura que o próprio Lévi-Strauss, ainda que subterrânea e anacronicamente, nos forneceu via o multinaturalismo: uma outra possibilidade de se pensar a relação entre humanidade e animalidade pelo viés do perspectivismo ameríndio. Nas palavras do próprio Eduardo Viveiros de Castro, presentes no livro Há mundo por vir? Ensaio sobre os medos e os fins:

Perspectivismo ameríndio foi o nome que T.S.Lima e E.Viveiros de Castro escolheram para designar uma noção muito difundida na América indigena, segundo a qual cada espécie de existente vê-se a si mesma como humana (anatômica e culturalmente), pois o que ela vê de si mesma é a sua alma, uma imagem interna que é como a sombra ou o eco do estado humanóide ancestral de todos os existentes. A alma, sempre antropomorfa, é o aspecto dos existentes que estes enxergam quando olham para/interagem com os seres da mesma espécie - é isso, na verdade, que define a noção mesma de espécie.
A forma corporal externa de uma espécie é, portanto, o modo como ela é vista pelas outras espécies (essa forma é frequentemente descrita como uma roupa). Assim, quando um jaguar olha para um outro jaguar, ele vê um homem, um índio; mas quando ele olha para um homem - para o que os índios vêem como um homem -, ele vê um queixada ou um macaco, já que estas são algumas das caças mais apreciadas pelos índios amazônicos. Assim, todo existente no cosmos vê a si mesmo como humano; mas não vê as outras espécies como tal (isso, ocioso sublinhar, se aplica igualmente à nossa espécie). ${ }^{15}$

Notemos que o perspectivismo ameríndio, como nos mostra a definição apresentada, trata, em primeira instância especificamente dos animais quanto à condição variável de presa e predador. Mas não são só os seres em imediata relação de predação que enxergam a si mesmo como humanos. Essa categoria pode e deve ser estendida aos demais animais, e mesmo aos vegetais - especialmente tratando-se do povo Huni Kuĩ, que tem plena consciência de que as plantas e legumes são também humanos, ainda que transformados. ${ }^{16}$ Assim, o pica-pau do mito, mesmo que não seja parte de uma relação predatória evidente, certamente se encaixa nos moldes teóricos perspectivistas, ou seja, é possível imaginar que também ele se vê como humano, ainda que ao potencialmente matar um homem com o seu canto ele não o esteja fazendo por conta de uma cadeia alimentar. ${ }^{17}$ Mesmo os
15. DANOWSKI; VIVEIROS DE CASTRO. Há mundo por vir?, p. 95.

16. O próprio Eduardo Viveiros de Castro, em suas Metafísicas canibais, prevê a ampliacãa do escopo de sua teoria: "Pois se nem todos os existentes são pessoas de facto, o ponto são pessoas de facto, o ponto impede (de jure) que que nada espécie ou modo de ser o seja. Não se trata, em suma, de um problema de taxonomia, crassificação, de 'etnociência'. Todos os animais e demais. componentes do demas são intensivame virtualmente pesso pessoas, qualuer um deles pode qualquer um deles pode se pessoa. Não se trata de um) uma pessoa. Não se trata de uma mera possibilidade lógica, mas (VIVEIROS DE CASTRO. Metafísicas canibais, p. 45-46).

17. Aliás, para os Yanomami, por exemplo, esse outro povo da floresta, toda forma de agressão letal, seja ela humana ou náo humana, e tomada também como uma forma de predação. Cf. ALBERT; $\mathrm{KC}$ do céu. 
humanos humanos (ou seja, nós, que nos enxergamos como humanos) não matamos exclusivamente para nos alimentarmos. Existem outras relações distintas das de predação estritamente alimentar que resultam na morte. Tekã Kuru, por exemplo, matou a esposa por vingança, um homem encantado por defesa, um gavião por necessidade etc. Dessa maneira, parece ser a morte, e não mais a música, o que de fato interessa no canto do pica-pau.

Os povos da floresta, ao enxergarem a cultura na natureza (o humano no animal, o saber na vida nua) estão dotando todos os seres existentes de uma mesma capacidade de agência, ou seja, de interferir na ordem social (ou mesmo cosmológica) por meio de uma ação individual. Assim, se os humanos são capazes de, por exemplo, praticar rituais, caçar, tomar o cauim e fazer festa, também os animais o são. Se os homens podem matar outros seres sem sequer tocar em sua vítima, por meio de feitiços ou da fabricação de veneno, também os animais o podem. O canto do pica-pau, desvelando-se o véu perspectivista e traduzindo-o para a natureza humana, não seria nada além de um encantamento ou veneno destinado a matar quem o escuta. Se anteriormente nos esforçamos para equiparar o canto do pica-pau à música humana, foi por enxergarmos ambos os fenômenos como produções de sensível análogas, isto é, de uma mesma natureza ou relação genética. Apoiando-nos no perspectivismo ameríndio, percebemos que o canto mortífero do pica-pau embora esteja, como a música, do lado da cultura - como quis Levi-Strauss - difere dessa última em suas potencialidades e desempenha, pelo menos nessa narrativa huni kuĩ, um papel diferente, que vai além dos âmbitos da comunicação e da expressão.

Em "Fumaça do tabaco", Tekã Kuru ignora o alerta da irmã e, ao ver o pica-pau se aproximar cantando, rapidamente o mata com sua borduna. Ironicamente, Tekã Kuru irá perecer envenenado, após comer o fígado de uma outra ave, o urubu. Tal desfecho trágico parece-nos evocar a ideia de nisũ, palavra em Hãtxa Kuĩ que designa um estado doentio provocado, entre outras coisas, pela ingestão de alimentos animais e/ ou vegetais. O nisũ é como uma vingança, um veneno ou feitiço lançado naquele que come pelo ser que morreu e virou alimento. Somos tentados mesmo a acreditar que a morte de Tekã Kuru seja, de uma maneira ou de outra, uma vingança do pica-pau assassinado. Coisa que só é possível, para nós brancos e modernos, na literatura, nunca naquilo que chamamos de realidade.

Em uma conversa com o professor Joaquim Mana Kaxinawá, tomamos conhecimento de que o pica-pau é o mensageiro espiritual do seu povo, que dialoga constantemente com os pajés ("sábios espirituais", nas palavras do professor) e que traz, por meio desse diálogo, coisas boas e ruins, relacionadas à vida e à morte. Por isso, não se deve tomar o que aqui propomos nas entrelinhas de nossas reflexões - a 
existência real do pica-pau da história de Tekã Kuru - por uma assunção ingênua que implicaria consequências cômicas ou ridículas aos olhos dos brancos: quando os Huni Kuĩ veem um pica-pau, eles não saem correndo, com medo de serem mortos. O que eles fazem de diferente de nós brancos é saber da importância desse ser para a vida de seu próprio povo, e por isso respeitam o poder desse animal humano, como de todos os outros seres.

Para que tudo isso aqui ensaiado faça o mínimo de sentido, é preciso salientar que o perspectivismo ameríndio parte de um lugar de fala diferente do de Lévi-Strauss. Ao incorrer em um antropocentrismo incômodo, o autor das Mitológicas o faz por conta de seu intento de buscar compreender o pensamento mítico a partir do pensamento racional (condição imposta pelo fazer científico a que se propôs, razão de sua ousadia e genialidade e, ao mesmo tempo, da contradição fragilidade de sua empresa). O pica-pau do mito huni kuĩ é um ser inconcebível para Lévi-Strauss porque o antropólogo fala do lugar do homem branco, ocidental, irremediavelmente racionalista. Ao admitir a possibilidade de existência um pica-pau de tal sorte, ele estaria colocando em xeque todo o pensamento ocidental cartesiano, implodindo, consequentemente, seu próprio trabalho e obra. Já o perspectivismo ameríndio de Eduardo Viveiros de Castro supostamente propõe uma revisão de nossas cosmologias e ontologias a partir do pensamento dos povos extra-ocidentais, lugar onde habita o pica-pau da história de Tekã Kuru. Portanto quando só o pensamento mítico e a literatura podem conceber um pica-pau capaz de matar alguém com seu canto, isso parece nos indicar que a literatura está mais próxima dos povos da floresta do que se imagina. E isso quer dizer que temos muito o que aprender com eles, mesmo nessa matéria que acreditamos ser tão e somente nossa, a literatura.

Não nos ocupamos, nesse ensaio, de elaborar proposições acerca do Mito, nem de pensar a Literatura, nem sequer de analisar a narrativa "Fumaça do tabaco" em sua completude. Acreditamos, porém, que tenhamos discursado sobre a relação entre os três sob o pretexto da curiosidade, incitada por um pequeno detalhe do mito de Tekã Kuru. No início desse ensaio, havíamos dito que não sabíamos que pica-pau cantava. Agora, após enredar-nos por esse atípico assunto, parece-nos clara a razão de tal ignorância: O pica-pau é um ser caprichoso, que só canta para quem quer ouví-lo. Por isso os Huni Kuĩ possuem consciência de seu canto. Para nós - brancos, modernos ou ocidentados - ele só faz o tec-tec do seu bico contra a madeira. É um gesto (cosmo)político. Se há alguma lição que possa ser tirada dessa pequena investigação a que nos propomos, é a de que ler a literatura indígena e estabelecer o outro como destino ${ }^{18}$ é uma maneira de burlarmos a surdez intrínseca à nossa identidade ocidental e escutarmos o canto do pica-pau, não para morrermos, mas para vivermos.
18. Evoca-se aqui a célebre formulação de Eduardo Viveiros de Castro, "Para o Tupi, o outro não é um espelho, é um destino". 
19. LÉVI-STRAUSS. O homem nu, p. 667
P.S.: Curiosamente, e como ótima ilustração do caráter positivamente contraditório de Lévi-Strauss, na ponta das Mitológicas diametralmente oposta à nota de rodapé de $O \mathrm{cru}$ e o cozido sobre o "pretenso" canto dos pássaros, i.e., no finale de $O$ homem nu, o leitor se depara com o seguinte excerto:

Sua indefinível beleza [do canto dos pássaros] escapa a qualquer descrição em termos acústicos, pois as modulações são tão rápidas e tão complexas que o ouvido humano não as percebe ou só percebe partes. Essa suntuosidade secreta aparece, contudo, discretamente legível em forma geométrica nos oscilogramas nos quais, traduzidos em gráficos, os cantos das diversas espécies se tornam para nós perceptíveis na totalidade em formas incrivelmente delicadas e refinadas (Greenwalt 1969) e que evocam extraordinárias obras-primas de marfim ou de algum outro material precioso, esculpidas no torno. ${ }^{19}$

KAXINAWÁ, Joaquim Paulo de Lima Mana e outros (Org.).

Shenipabu Miyui: história dos antigos. 2.ed. rev. Belo Horizonte: Ed. UFMG, 2008

KOPENAWA, Davi; BRUCE, Albert. A queda do céu: palavras de um xamã yanomami. São Paulo: Companhia das Letras, 2015.

LÉVI-STRAUSS, Claude. Mitológicas I (O cru e o cozido). São Paulo: Cosac \& Naify, 2004

LÉVI-STRAUSS, Claude. Mitológicas IV (O homem nu). São Paulo: Cosac \& Naify, 2011

NUNES, Benedito. O animal e o primitivo: os Outros de nossa cultura. Historia, Ciências, Saúde, Manguinhos, v 14, n. 4 , p. 279-290, 2007

VIVEIROS DE CASTRO, Eduardo. Metafísicas canibais. São Paulo: Cosac Naify, 2015

Aqui, o canto dos pássaros já não é "pretenso", mas suntuoso, delicado e refinado. Se Lévi-Strauss não pode ouvir esse canto, ele pode, pelo menos, vê-lo.

\section{REFERÊNCIAS}

COCCIA, Emanuele. A vida sensível. Desterro. Florianópolis:

Cultura \& Barbárie, 2010

DANOWSKI, Déborah; VIVEIROS DE CASTRO, Eduardo. Há mundo por vir? Ensaio sobre os medos e os fins. Desterro: Cultura e Barbárie: Instituto Socioambiental, 2014.

EM TESE

BELO HORIZONTE

v. 22

N. 2

MAIO-AG0. 2016

SOUZA. Kãns kãns karã̃: 0 canto do pica-pau 